\title{
MODELING THE SPATIAL DEVELOPMENT OF THE ECONOMY ON THE BASIS OF PERSPECTIVE INTERREGIONAL COOPERATION AND SPECIALIZATION
}

\author{
Julia DUBROVSKAYA ${ }^{a *}$, Elena KOZONOGOVA ${ }^{b}$ \\ ${ }^{a, b}$ Perm National Research Polytechnic University, Russian Federation
}

DOI: $10.24818 / \mathrm{IMC} / 2020 / 05.14$

\begin{abstract}
The paper presents a methodology for modeling the spatial development of the economy on the example of Russia. The relevance of the study is due to the need to ensure the rational use of the country's territorial space by the authorities, which implies taking into account the system of classical factors of economic zoning: the availability of transport and social infrastructure, the optimization of the settlement system and the location of production facilities. Modeling of spatial development is carried out by building an optimization model for identifying macroeconomic regions. The minimum level of spatial development heterogeneity was selected as an optimality criterion between the regions included in the macroregions and between the macroregions of the country by calculating the Theil index. The model is based on the concept of product space and the assumption that the optimal macroregions provides high rates of the Economic Complexity Index. Thus, the methodology for constructing a model of spatial development includes determining the composition of the equations system and their structure, formulating the assumptions and limitations of the model, and determining the objective function of the model. The visualization of the results is based on the construction of a graph, the vertices of which are the types of production activities in the macroregion. The final formalization of the model presupposes obtaining a system of macroregions that provide a high diversification of the types of production activities; minimizing the heterogeneity of the spatial development; determination of the promising specialization of the macroregion as it develops.
\end{abstract}

KEYWORDS: macroregions, spatial heterogeneity, the Economic Complexity Index, optimtzation model, product space

\section{INTRODUCTION}

A long-term study of the problem connected with the heterogeneity of the regional development in Russia (Dubrovskaya et al., 2018; Kozonogova \& Dubrovskaya, 2019; Kozonogova et al., 2019), including a detailed evolutionary analysis of the reforming the country's administrative-territorial division over the past 100 years, allowed us to identify an important feature of the spatial organization of the economy in this country: the classic transition from diversification to specialization mentioned by Imbs \& Wacziarg (2003), Klinger \& Lederman (2006), Cadot et al. (2011) is unacceptable for the Russian regions, it is an utopian way of development. This is due to the historically formed administrative-territorial structure of the country, which started to develop under the communist system of government. Note that the basic principles of the country's economic zoning were developed by 1921. According to these principles, an economic region is formed by geographical conditions and a settlement system and is one of the links in the overall chain of the national economy (Izyumova \& Berger, 2015). In the context of the virtual absence of

\footnotetext{
*Corresponding author. E-mail address: uliadubrov@mail.ru
} 
non-state ownership forms, monopolization of the political space by the only mass party, underdevelopment of civil society institutions, interest groups were not autonomous and independent of the statist government (Peregudov, 2003). So, a stable specialization of the regions took shape in Russia within the framework of the territorial reforms have been carried out by the Bolsheviks since 1920. According to the reformers' plan, the interaction of regions within the framework of uniform territorial-industrial sets was supposed to ensure a full-fledged uniform development of industries. It is known that the methodology for drawing up a GOELRO's plan was based on the principle of identifying the main link in the structure of the regional economy (the state plan for the electrification of Soviet Russia, adopted in 1920 and became the first perspective plan for the spatial development of the Russian economy). Thus, there was a "concentration of economic activity of a certain type in the territories where the resources of labor and capital most favorable for this type of activity are concentrated" (Minakir et al., 2020). The specialization of the region's economy was consolidated in order to comply with the necessary proportionality of the national economy development as a whole by ensuring the same growth rates for all sectors (Morozova, 2011; Izyumova \& Berger, 2015). The positive side of specialization was that it was accompanied by interregional cooperation in production, strengthening and development of interregional economic ties.

The radical economic reforms and disintegration processes of the 90s of the last century had a negative impact on the state of the economic space of the Russian Federation. A significant part of the formed production and trade ties both within the country and between the former republics of the USSR was broken. As a result, the differentiation of the conditions for economic activity has significantly increased, and the total volume of interregional economic ties, according to experts, has decreased by 4 times. This led to an increase in autarkic tendencies and regional separatism. Thus, the passage of the diversification stage for regional economies (including adherence to export diversification strategies called for by a number of scientists (AEC) and the subsequent choice of specialization is not possible in practice due to the duration, uncertainty and cost.

The solution is to create a diversified economic structure within the macro-regions, which include several regions specializing in the production of various products. Thus, the territories interacting within the macroregion as a single territorial structure have every chance to reach the core of the food space, producing goods with high added value in cooperation.

Indeed, it is interregional interaction that is recognized by many scientists (Rastvortseva, 2020; Bakumenko, 2017, 71; Belousova, 2012) as the most important component of spatial development policy. At the same time, one must not forget that the enterprises are the main interacting economic agents that ultimately determine not only the location of production factors, but also the dynamics of growth and the scale of development of the territory. Therefore, we fully share the point of view that "the task of maintaining general economic equilibrium as a whole is reduced to the task of influencing the economic behavior of microeconomic agents in order to create such a spatial distribution of values of micro- and macroeconomic parameters (average and marginal costs of factors of production, prices of goods and services, prices of factors, incomes, savings, employment, institutional parameters, etc.), under which rational decisions of microeconomic agents will correspond to the formation of regional economic equilibria” (Minakir \& Demyanenko, 2010, 23). Therefore, in this study, we proceed from the fact that the allocation of a system of macroregions, as the basis for achieving the core of the product space, requires not only taking into account the classical factors of economic zoning (availability of transport and social infrastructure, optimization of the settlement system and location of production facilities), but above all needs in determining the directions of promising interregional cooperation of enterprises.

Thus, the purpose of this study is the mathematical formulation of the dynamic modeling problem of the economy spatial development on the basis of promising interregional cooperation. 


\section{LITERATURE REVIEW}

Ensuring the rational use of limited territorial space is a key function of government bodies at any level. These major issues originate in the theories of absolute (A. Smith) and relative (D. Ricardo) advantages of international trade, which actualized the importance of production specialization. As Minakir $(2010,13)$ notes, the theory of international exchange by A. Smith and D. Riccardo "was based on empirical observations about the differences in the productivity of production factors at different points in the economic space."

Directly, the issues of expediency and rationality of the production facilities spatial allocation were widely disclosed in the works of German scientists Thunen J. H. (1926), Launhardt W. (1882), Weber A. (1929), Christaller W. (1980), a significant theoretical base has been formed regarding the spatial localization of production and the vital activity of the population. At the same time, the economies of most countries (especially those with large territories) are not uniformly developed, since «the spatial economy is very heterogeneous because the population and industries are not uniformly scattered in space, they are agglomerated in specific locations, leading to the exclusion from the economic system of those territories and regions that do not have the capacity to attract industries and population» (Andres-Rosales et al., 2018, 62-63).

Indeed, spatial studies are most relevant for countries with a large territory. Scientists investigate such important components of spatial development as transport infrastructure, localization of production facilities, settlement system. In general, spatial development refers to the improvement of the settlement system and the territorial organization of the economy. But what does the improvement of territorial organization mean for a country with such a large area as, for example, Russia? It is obvious that the rational organization of space should be specified by some criterion of optimality. As Minakir notes, the achievement of the Pareto-optimal state of the national economy in the spatial aspect is possible when, within each territorial economic subsystem (region), resources are used in an optimal way, and, therefore, the total public resources are allocated and used optimally (Minakir, 2005, 12).

But finding a single criterion for the optimality of the spatial organization of the economy is an extremely difficult task with many unknowns: investments in the development of which industries, infrastructure projects and territories as a whole will bring maximum productivity and utility for the country; how to fairly distribute the received factor income; which is more important - rapid growth or gradual development? At least, "we are faced with a choice between spatial and temporal factors, because preference for efficiency means a preference for rapid growth, increase in income over time, and public benefit involves taking into account the interests of specific groups of the population, development of specific territories” (Minakir, 2005, 5).

The complexity and importance of solving the problem of the optimal space organization is the reason for the increased interest of scientists in this issue. It has been proven that the ineffective spatial organization of activities in the country, including ineffective distribution of the population, lack of resources at points of real growth, ineffective design of transport communications, costs it a loss of at least 2-3\% of GDP annually (RPSD). In addition, recent studies have shown that the consequences of spatial inequality are not only economic, but also social and political ones (Iammarino et al., 2019).

Speaking about social problems, one cannot ignore the obvious consequences of the heterogeneous development of territories within a single country. So, for example, despite the fact that the main task of the state policy of spatial development in Russia is "to reduce interregional differences in the level and quality of life of the population," (SDSRF, 2019) the volume of GRP per capita in the leading regions of our country is comparable to that of countries belonging to the "Group of Seven"; at the same time, the per capita GRP of the poorest constituent entities of the Russian Federation is lower than in many of the poorest countries on the African continent. Thus, economic problems give rise to social tension and inevitably lead to political problems. 
The main tool for solving the problem of reducing spatial heterogeneity is economic regionalization. The accumulated experience of the United States and Russia in the management of socio-economic systems proves the positive results of territorial defragmentation of economic policy. The emergence of the strategy of regional growth poles, special economic zones, the cluster concept, the theory of diffusion of innovations, the concept of product space and other innovations in the field of territorial organization on this basis had a strong impact on the improvement of the theory of placement. At the same time, researchers have not yet come to an agreement on which of the two basic strategies for territorial development is more effective: diversification of industries or concentration (specialization).

On the one hand, it is obvious that the highly diversified structure of the economy determines new ways of development (Hidalgo et al., 2007; Neffke et al., 2011; Hausmann \& Klinger, 2007) «because the set of competences and assets that a region possesses determines what new paths and new industries this region is able to develop» (Zhu et al., 2015). Moreover, on the example of Russian regions, it was revealed that richer territories have large coefficients of uneven distribution in the sectoral structure of GRP (Eskerkhanov \& Shamilev, 2014). Thus, the possibilities for the development of the territory should not be limited by the existing sectoral structure of the economy, since innovative development is possible only on the basis of reaching the core of product space (the term coined by Hidalgo, 2007) which includes most upscale products.

On the other hand, the highly developed countries of the European Union are successfully interacting within the framework of the concept of "smart specialization". This concept was implemented on the smart specialization platform (SSP) in 2011 by Institute for Prospective Technological Studies. The platform helps the countries of the European Union in choosing a specialization by comparing their own capabilities with the capabilities of other territories, assessing their own competitiveness, identifying target markets and industry priorities. It is important to note that it was specialization, or, more simply, concentration, that was the basis for the methodology of economic regionalization in the Soviet Union at the beginning of the 20th century. The specialization of the economic region was consolidated in order to comply with the necessary proportionality of the development of the national economy as a whole by ensuring the same growth rates for all sectors (Morozova, 2011, 12; Izyumova \& Berger, 2015, 145).

At the same time, there is an objective criticism of specialization. Thus, having studied the regional policy of equalization in European countries, implemented in the last two decades, D. Puga (2002) comes to the conclusion that the development of various specializations by European states has led to an increase in both the differentiation between regions within each state and to the polarization of unemployment levels (Puga, 2002). The Russian researcher E. Kolomak comes to similar conclusions, she has proved that due to increased competition and vulnerability of regional economies, an increase in the level of specialization in the regions of the Russian Federation leads to a decrease in the concentration of production and worsens labor productivity indicators on the territory (Kolomak, 2013, 147).

Thus, the idea that the choice between specialization and diversification of the economy is in the field of the level of a specific socio-economic system development deserves increased attention. In particular, Asian economies such as South Korea, Taiwan, Singapore and China left the group of poor countries, partly as a result of the choice of export diversification strategy (AEC). Thus, the activation of economic growth is possible at the initial stage of development by introducing innovations for the production of goods with high added value. This allows the implementation of the export diversification strategy mentioned by Imbs \& Wacziarg (2003), Klinger \& Lederman (2006), Cadot et al. (2011). In future «high income countries ultimately re-concentrate their exports towards fewer products» (Cadot et al, 2011).

It means that, it is exactly diversification, and not concentration (specialization), that allows the economy to grow faster at the initial stages of development. Moreover, regardless of the level of development, «structure of the product space affects potential changes in a country's pattern of 
specialization» (Hidalgo et al.,2007, 4). As a result, we can conclude that diversification is the basis of promising specialization.

\section{RESULTS AND DISCUSSIONS}

\subsection{Evolution of spatial development modeling}

Mathematical models provide a systematic understanding of problems and allow taking into account simultaneously all factors affecting them. Building a general spatial economic equilibrium model is not an easy task. Such a model should synthesize the entire set of private placement theories and include a logical and mathematical description of the conditions for the location of production and transport networks, settlement and migration of the population, the formation of regional markets and interregional trade.

It is customary to associate the first attempts at mathematical substantiation of the spatial development quality of a territory with A. Losch (2007), the creator of the theory of spatial economic equilibrium, and his main work "Spatial organization of the economy", published in 1940. It was in it that All well-known theories of the location of production were analyzed exactly in this paper, as well as a general theory of the economic space organization. In the sixties of the twentieth century, in order to form optimal scenarios of economic development, a class of multiregional intersectoral models was developed using the theory of general equilibrium and multipurpose optimization tools as a methodological base. The concepts of these models, which combine the conditions of intersectoral and transport tasks, were formulated by W. Isard, L. Moses and B. Stevens.

Speaking about Russian scientists, it is important to note that the first intersectoral models were developed and tested in 1966-1975 under the leadership of academician A. Granberg. Their advantage was the ability to simulate and obtain scenario calculations, which is of undoubted interest for substantiating management decisions. Soviet scientists determined the optimal values of regional production volumes, volumes of interregional deliveries of products, as well as the amount of labor resources use and interregional distribution of investments. Further calculations based on updated data and improved methods were carried out in 1997 (assessment of the macroregions interactions) and in 2007 (construction of a spatial development forecast for federal districts). At the moment, the use of multi-regional models based on input-output balances is limited by the lack of statistical data for the regions of Russia. As a result, attempts to create a model for the spatial development of the Russian Federation are reduced either to the field of the redistribution of budgetary funds, or to the dynamics of export-import relations, or to the adaptation of existing macroeconomic models of intercountry interactions to the regional level.

Modeling the spatial development of the economy based on perspective interregional cooperation is supposed in this paper to be carried out by building an optimization model for identifying macroeconomic regions, its cartographic visualization and making a forecast regarding the choice of a perspective specialization of the macroregion.

It is assumed that productive cooperation of regions within each separate macroregion will ensure, firstly, a high diversification of the types of production activities of the macroregion as a whole; secondly, a decrease in the heterogeneity of the development of its constituent territories and maximum economic growth; thirdly, the definition of the perspective specialization of the macroregion as it develops.

The development of an economic and mathematical model of spatial development is carried out in two subsequent stages.

\subsection{Building an optimization model to identify the optimal structure of macroregions.}

Typically, optimization models are aimed at finding the extremum of a function. In our case, the minimum level of spatial development heterogeneity was selected as an optimality criterion 
between the regions included in the macroregions and between the macroregions of the country by calculating the Theil index. The model is based on the concept of product space and the assumption that the optimal macroregions provides high rates of the Economic Complexity Index (ECI).

The optimal structure of macroregions is determined using a simulation experiment divided into three steps. At each iteration, all regions are divided into macro-regions, taking into account the fact that each macro-region contains objects of social and engineering infrastructure. This condition will guarantee at least the preservation of the existing population and at the maximum its positive reproduction. Moreover, each of the regions included in the macroregion has a common border with at least one region. Then the Theil index and ECI are calculated for macroregions. N-iterations are performed in total.

Step 1. Theil index calculation

The gross regional product per capita at purchasing power parity is used as a variable for the calculation.

Theil index is calculated by the following formula:

$$
T_{m}=\sum_{r=1}^{R}\left(\frac{Y_{Y}}{Y} \ln \frac{Y_{Y}}{\frac{Y}{R}}\right)
$$

where $Y_{r}$ is the value of the variable in the region $\mathrm{r}, \mathrm{Y}$ is the value of the variable in the aggregated level, $\mathrm{R}-$ number of regions. Theil index ranges from 0 to $\ln R$. Extreme values correspond to absolute interregional equality ( $\mathrm{Yr}=\mathrm{Y} / \mathrm{R}$ ) and concentration of all activity in one region, respectively. The larger the index value is, the greater the spatial differences are.

Using the property of the index's separability, it is decomposed into components related to differences between macroregions and between territories within each of them. At the same time, the intergroup component characterizing the contribution of differences between macroregions is calculated by the next formula:

$$
T_{\text {between }}=\sum_{m=1}^{M} \frac{Y_{m}}{Y} \ln \frac{\frac{Y_{m}}{R_{m}}}{\frac{Y}{R}}
$$

where $Y_{m}$ is the indicator value for the macroregion $\mathrm{m}, R_{m}$ is the number of territories within the macroregion m. In this case it is obvious that $Y_{m}=\sum_{r=1}^{R_{m}} Y_{r}$.

Intra-group component characterizing the contribution of differences between the subjects of the Russian Federation within the macroregion is calculated as follows:

$$
T_{\text {within }}=\sum_{m=1}^{M} \frac{Y_{m}}{Y} T_{m}
$$

Theil index calculated for the macroregion territory:

$$
T_{m}=\sum_{r=1}^{R_{m}} \frac{Y_{r}}{Y_{m}} \ln \frac{Y_{r}}{\frac{Y_{m}}{R_{m}}}
$$

The value of the general Theil Index is calculated as follows:

$$
T=T_{\text {between }}+T_{\text {within }}
$$

Step 2. Calculation of the Economic Complexity Index 
According to the atlas of economic complexity edited by Ricardo Hausmann and César A.Hidalgo, economic complexity is a measure of how intricate this network of interactions is and hence of how much productive knowledge a society mobilizes (Hausmann et al., 18). Economic complexity, therefore, is expressed in the composition of a country's productive output and reflects the structures that emerge to hold and combine knowledge.

ECI calculation is carried out based on the method by Hausmann et al. (2011) using the data on the average number of employees for the full range of organizations in the studied regions by type of economic activity.

The choice of the "average number of employees" indicator when calculating the ECI instead of the Revealed Comparative Advantage (RCA) indicator used by the authors, based on the structure of a country's exports, seems to be the most reasonable when studying the regions of a single country. Firstly, the use of the average number of employees in the calculation of ECI helps to get rid of possible inaccuracies associated with the lack or information imperfection (for example, the discrepancy between the center of economic activity and the profit center, regional differences in wages and prices, etc.) (Dubrovskaya et al., 2017). Secondly, RCA based on the export indicator is inappropriate to use if the commodity structure of the country is homogeneous, as well as in countries with a large domestic market (Rastvortseva, 2020).

As far as ECI calculation is carried out using the "average number of employees" indicator, there is a need to exclude a number of intangible production sectors related to services, trade, transport due to the fact that they are significant suppliers for most industries. In addition, industries that are "useful" only for the region of their residence are excluded, that is, they supply goods and services only for the internal market of the region. Porter $(2003,559)$ called such sectors as «local industries».

Then the Economic Complexity Index is calculated for each macroregion in two steps.

Firstly, economic activities that have a comparative advantage are identified based on the localization factor to calculate the ECI $\left(L Q_{i r}\right)$ :

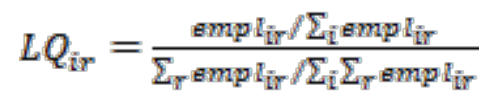

where $\mathrm{r}$ is the macroregion index, empl $\mathrm{er}_{\text {ir }}$ is the total number of people employed by type of activity $\mathrm{i}$ in macroregion $\mathrm{r}$ at time $\mathrm{t}, \sum_{i} e m p l_{i r}$ - is the total number of people employed in macroregion $\mathrm{r}$, $\Sigma_{r} e m p l_{i r}$ is the total number of people employed by type of activity i, $\sum_{i} \sum_{r} e m p l_{i r}-$ total employment in the country.

Secondly, the matrix $M_{r i}$ is formed, the rows of which are macro-regions, and the columns are types of economic activities. The matrix element is equal to 1 if the localization coefficient of the industry $\mathrm{i}$ is greater than 1 in the macroregion $\mathrm{r}$, and is equal to 0 otherwise. Diversity and ubiquity among macroregions is measured based on the matrix data:

$$
\begin{aligned}
& \text { diversity }=k_{r, 0}=\sum_{i} M_{r i} \\
& \text { ubiquity }=k_{i, 0}=\sum_{r} M_{r i}
\end{aligned}
$$

An estimation of the average diversity of macroregions producing goods of a particular industry, and an average estimate of the ubiquity of the activities distribution by macroregions can be obtained using recursion:

$$
\begin{gathered}
k_{r_{i} N}=\frac{1}{k_{r i 0}} \sum_{i} M_{r i} \times k_{i, N-1} \\
k_{i_{i} N}=\frac{1}{k_{i, 0}} \sum_{r} M_{r i} \times k_{r, N-1}
\end{gathered}
$$


If we put the equation (9) into the equation (10), we will get the following:

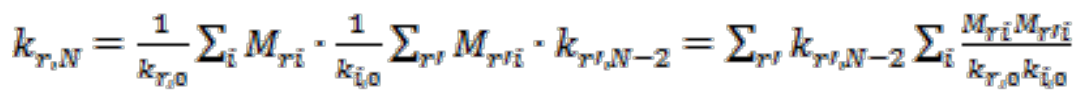

Rewrite the equation (11) in the following way:

$$
k_{r_{2} N}=\sum_{r y} M_{r r l} k_{r^{I}, N-2}
$$

where

$$
M_{r r l}=\sum_{i} \frac{M_{r i} M_{r r i}}{k_{r_{i} 0} k_{i j 0}}
$$

Thus, ECI can be determined using the next formula:

$$
E C I=\frac{\vec{K}-\operatorname{mean}(\vec{K})}{\operatorname{std} \operatorname{sev}(\vec{K})}
$$

where $\vec{K}$ - eigenvector that corresponds to the second largest eigenvalue of the matrix $M_{r r y}(13)$.

Step 3. Determination of the macroregions optimal structure

At each iteration $\mathrm{j}(j=1, n) k_{j}$ macroregions are determined. The regions included in the macroregion will be denoted as the set E. Then, after each iteration, the set $E_{j}=\left\{E_{1}, E_{2}, \ldots, E_{k_{j}}\right\}$. is obtained. After carrying out n-iterations, the optimal structure of macroregions $E_{j}$ is determined. The set of macro-regions $E_{j}$ is considered to be the optimal one if the following conditions are met:

1. The value of the Theil index is minimal:

$$
T=\min _{j} T_{j}(Y)
$$

2. The Economic Complexity Index value for each macroregion is greater than the threshold level $\lambda$

$$
E C I_{r} \geq \lambda, r=\left(1, \dot{k}_{J}\right)
$$

3. There are certain objects of social and engineering infrastructure on the territory of the macroregion (according to the author's methodology (Dubrovskaya et al., 2019)).

\subsection{Choosing a perspective specialization of a macroregion based on visualizing its product space}

To determine the promising specialization of the macroregion, it is necessary to identify how close the economic sectors of the territories included in the macroregion are to each other. To do this, we proceeded from the theoretical assumption that «if two goods are related, because they require similar institutions, infrastructure, physical factors, technology, or some combination thereof, then they will tend to be produced in tandem, whereas highly dissimilar goods are less likely to be produced together» (Hidalgo et al., 2007, 483). Based on this, the potential for the emergence of related industries and their further development in the macroregion is high. This provides objective prerequisites for determining the perspective of specialization in the macroregion. 
For this purpose, the proximity index $\varphi_{i j}$ is calculated between industries $\mathrm{i}$ and $\mathrm{j}$ based on the conditional probability of having a comparative advantage. The calculation is performed using localization factors (formula 6) as follows:

$$
\varphi_{i j}=\min \left\{P\left(L Q_{i r}>1 \mid L Q_{j r}>1\right), P\left(L Q_{j r}>1 \mid L Q_{i r}>1\right)\right\}
$$

Based on the matrix, the elements of which are the proximity indices between industries $\mathrm{i}$ and $\mathrm{j}$, a visual representation of the product space in the macroregion is built. The product space of a macroregion is presented in the form of a graph, where the vertices of the graph are types of economic activities. Two vertices are connected by an edge if the proximity index $\varphi_{i j}$ is more than the threshold. At the same time, it is believed that two sectors of the economy can be characterized as related if the proximity index is equal to or exceeds 0.25 (Rastvortseva, 2020). The color of the top of the graph depends on which class the type of activity belongs to according to Russian Classification of Types of Economic Activity (OKVED). Figure 1 shows an example of visualization of a product space.

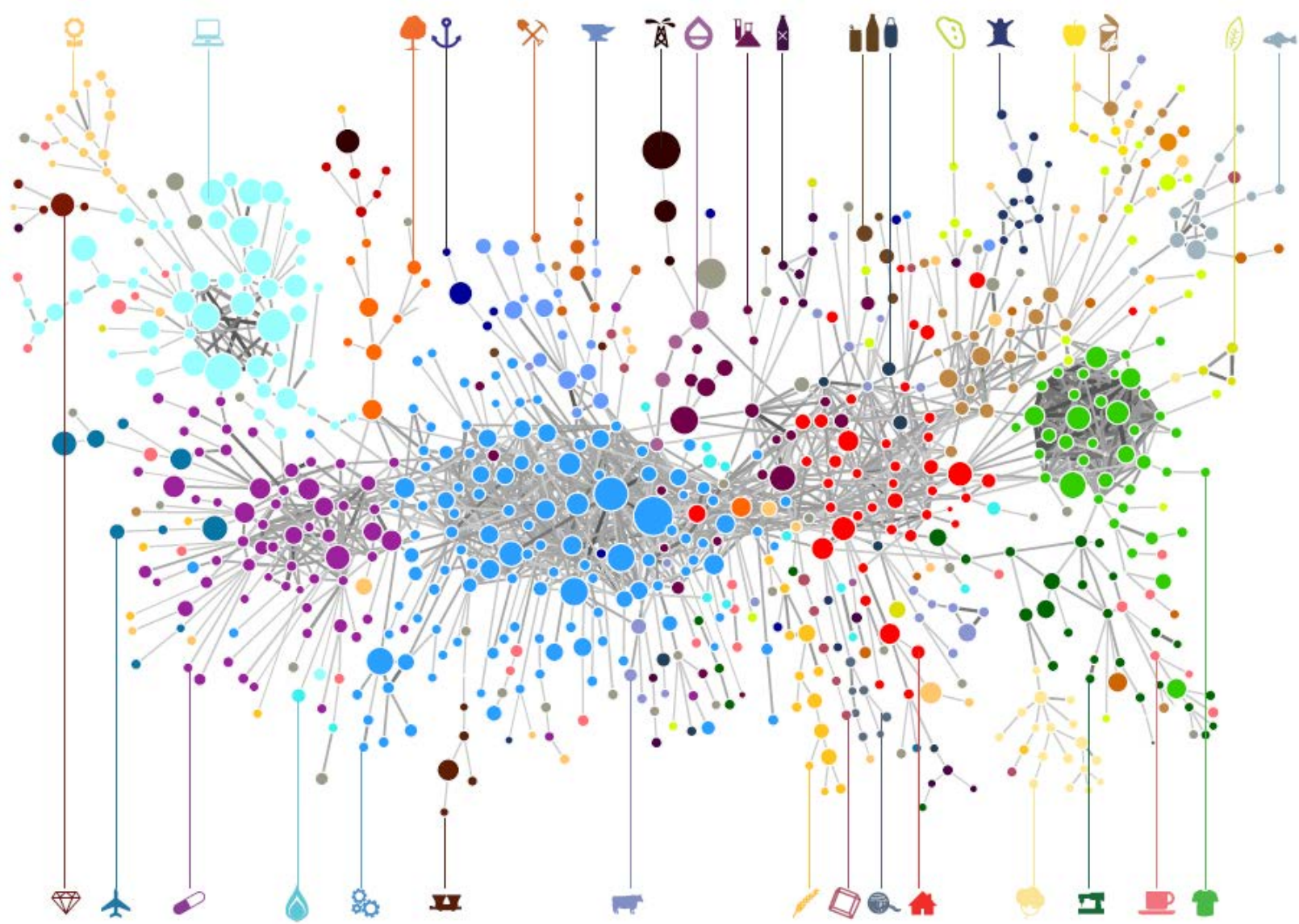

Figure 1. The product space

Source: adapted from Hausmann et al. $(2013,52)$

Further, the place of a particular region in the product space of the macroregion is determined. Understanding of the term «region's knowledge set» expressed by the current structure of the gross regional product is very important here. It has been proven that the accumulated knowledge, technologies and operating institutions determine the transition possibility of the region's economy to a new development trajectory (Neffke et al., 2011). Therefore, it is important to compare the production capabilities of the product of interest with the existing region's knowledge set. The 
calculated measure is called distance (d) and is calculated based on the share of knowledge needed to produce the product, but not available in the region:

$$
d_{r i}=\frac{\sum_{r}\left(1-M_{r i}\right) \varphi_{i i l r}}{\sum_{i V} \varphi_{i i l}}
$$

That is, if in the considered region there is a large part of the activities related to the industry of interest, then the distance will be close to 0 . And vice versa, if there are very few activities in the considered region related to the industry of interest, then the distance will be close to 1 .

Further, in order to predict the possibilities of improving the position of the region in the product space, an assessment is made of how close the structure of the economy of the region under consideration is to the types of activities the region does not produce:

$$
\text { complexityoutlook }_{r}=\sum_{i j}\left(1-d_{r i}\right)\left(1-M_{r i}\right) P C I_{i v}
$$

where PCI - Product Complexity Index, which is calculated according to the formula $P C I=\frac{\vec{Q}-\operatorname{mean}(\vec{Q})}{\operatorname{stdev}(\vec{Q})}, \vec{Q}$ is the eigenvector that corresponds to the second largest eigenvalue of the matrix $M_{r r v}(13)$.

Thus, The Complexity Outlook Index (COI) measures the position of the region in the product space. The larger the COI value is, the closer the region under consideration is to high-tech activities. Visual interpretation of the position of each region in the product space of the macroregion by constructing a graph with activities as peaks allows us to determine the perspective specialization of the macroregion.

\section{CONCLUSIONS}

The paper presents a mathematical target-setting for spatial development modeling of the economy on the basis of perspective interregional cooperation on the example of Russia. Such classical factors of economic zoning as the availability of transport and social infrastructure, optimization of the settlement system and the location of production facilities were taken into account when constructing the model. An optimization model for identifying macroeconomic regions has been developed, using the concept of a product space. The choice of the optimal system of macroregions was made by minimizing the heterogeneity of spatial development both between the regions included in the macroregions and between the macroregions of the country by calculating the Theil index, as well as the assumption that the macroregions have a regional structure that provides high values of the the Economic Complexity Index.

The novelty of the proposed methodology is the obtaining of the structure of macroregions, providing, firstly, a high diversification of the production activities types in the macroregion as a whole; secondly, a decrease in the heterogeneity of its constituent territories development and maximum economic growth; thirdly, the definition of the promising specialization of the macroregion as it develops.

The developed methodology is universal and can be applied to simulate the spatial development of the economy by countries mainly with large territories. In the future, the authors will test the model in the regions of the Russian Federation in order to predict and strategize the spatial development of the economy.

The main goal of the upcoming research is to develop and register a software tool that allows, firstly, automatically update data based on site parsing; secondly, to conduct simulation experiments to find the optimal variant of the spatial organization of the economy, taking into account promising interregional cooperation. 


\section{ACKNOWLEDGMENT}

The reported study was funded by RFBR according to the research project № 19-010-00562.

\section{REFERENCES}

Andres-Rosales, R., Bustamante Lemus, C., \& Ramirez Argumosa, G. S. (2018). Social exclusion and economic growth in the Mexican regions: A spatial approach. Investigaciones Regionales - Journal of Regional Research, 40, 57 -78

Atlas of economic complexity. Method description (AEC). In Atlas of economic complexity of Russian regions. $\quad$ Retrieved June 17, 2020, from https://ipei.ranepa.ru/images/docs/Atlas_Method.pdf

Bakumenko, O. A. (2017). Interregional interaction as a factor in the development of regional socio-economic systems (on the example of the North-West Federal District). (Dissertation for the degree of candidate of economic sciences, Pskov, 2017). Retrieved from http://www.iresras.ru/uploads/2017/Dissertaciya\%20Bakumenko.pdf

Belousova, A. V. (2012). Interregional interactions: impact on the regional economy (Khabarovsk Territory). Spatial Economics, 4, 127-137.

Cadot, O., Carre, C., \& Strauss Kahn, V. (2011). Export Diversification: What's behind the Hump? The Review of Economics and Statistics, 93(2), 590-605.

Christaller, W. (1980). The central places in southern Germany. An economic-geographical study of the regularity of the distribution and development of settlements with urban functions. Scientific Book Society, Darmstadt.

Dubrovskaya, J., Kozonogova, E., \& Pestereva T. (2019). Evaluation of the State Strategy of Spatial Development Effectiveness of the Russian Federation: A Cluster Approach. Eurasian Economic Perspectives: Proceedings of the 28rd Eurasia Business and Economics Society Conference, Coventry, UK, 131-140

Dubrovskaya, J., Kozonogova, E., \& Rusinova M. (2018). Evaluation of the factors forming the competitive regional development advantages: international experience. International Relations 2018: Current Issues of World Economy and Politics, Bratislava, 146-151

Dubrovskaya, Y. V., Kudryavtseva, M. R., \& Kozonogova, E. V. (2017). Smart Benchmarking as a Basis for Strategic Planning in Regional Development. Economic and Social Changes: Facts, Trends, Forecast, 11, 3, 100-116. DOI 10.15838/esc.2018.3.57.7

Eskerkhanov, L. Yu. \& Shamilev, S. R. (2014). Unevenness of socio-economic development of regions of the Russian Federation. Modern problems of science and education, 5, 391.

Hausmann, R. \& Klinger, B. (2007). The Structure of the Product Space and the Evolution of Comparative Advantage. Harvard University Center for Economic Development.

Hausmann, R., Hidalgo, C., Bustos, S., Coscia, M., Simoes, A., \& Yildirim, M. (2013). The Atlas of Economic Complexity: Mapping Paths to Prosperity. Massachusetts Institute of Technology and Center for International Development, Harvard University. Retrieved from https://growthlab.cid.harvard.edu/files/growthlab/files/atlas_2013_part1.pdf

Hausmann, R., Hidalgo, C., Bustos, S., Coscia, M., \& Yildirim, M. (2011). The Atlas of Economic Complexity: Mapping Paths to Prosperity. Cambridge: Center for International Development, Harvard University, MIT.

Hidalgo, C. A., Klinger, B., Barabasi, A. L., \& Hausmann, R. (2007). The product space conditions the development of nations. Science, 317, 482-487.

Iammarino, S., Rodriguez-Pose, A., \& Storper, M. (2019). Regional inequality in Europe: evidence, theory and policy implications. Journal of Economic Geography, 19, 273-298. doi:10.1093/jeg/lby021 
Imbs, J. \& Wacziarg, R. (2003). Stages of Diversification. American Economic Review, 93(1), 6386.

Izyumova, O. N. \& Berger, Yu. A. (2015). The historical aspect of the economic zoning of Russia. Bulletin of the Irkutsk State Economic Academy (Baikal State University of Economics and Law), 6(3), 140-150. DOI: 10.17150/2072-0904.2015.6(3).36.

Klinger, B. \& Lederman, D. (2006). Diversification, Innovation, and Imitation Inside the Global Technological Frontier. World Bank Policy Research Working Paper Series

Kolomak, E. A. (2013). Uneven spatial development in Russia: explanations of the new economic geography. Problems of Economics, 2, 132-150.

Kozonogova, E. \& Dubrovskaya, J. (2019). Assessment of the Features of the Spatial Organization of the Russian Economy Based on the Global and Local Moran Indices. Eurasian Economic Perspectives :Proceedings of the 28rd Eurasia Business and Economics Society Conference, Coventry, UK, 195-203

Kozonogova, E., Elokhova, I., Dubrovskaya, J., \& Goncharova, N. (2019). Does state cluster policy really promote regional development? The case of Russia. IOP Conference Series: Materials Science and Engineering, 497, 1-7. Retrieved July 10, 2020, from URL: https://iopscience.iop. org/article/10.1088/1757-899X/497/1/012044

Launhardt, W. (1882). Determining the most appropriate location for a commercial facility. Journal of the Association of German Engineers, 26, 106-115.

Losch, A. (2007). Spatial organization of the economy. Moscow: Nauka Publ.

Minakir, P. A. (2005). Economy and Space. Spatial Economics, 1, 4-26

Minakir, P. A. \& Demyanenko, A. N. (2010). Spatial Economics: Evolution of Approaches and Methodology. Spatial Economics, 2, 6-32.

Minakir, P. A., Isaev, A. G., Demyanenko, A. N., \& Prokapalo, O. M. (2020). Economic MacroRegions: An Integration Phenomenon or Political-Geographical Feasibility? The case of the Far East. Spatial economics, 16. 1. 66-99,67. Retrieved July 19, 2020, from https://dx.doi.org/10.14530/se.2020.1.066-099

Morozova, N. I. (2011). Actual value of the Soviet experience of territorial planning and rational location of production. Vestnik AGTU. Ser. Economics, 12-16

Neffke, F., Henning, M., \& Boschma, R. (2011). How do regions diversify over time? Industry relatedness and the development of new growth paths in regions. Economic Geography, 87(3), 237-265. DOI: https://doi.org/10.1111/j.1944-8287.2011.01121.x

Peregudov, S. P. (2003). Corporations, society, the state: the evolution of relations. Science, 37

Porter, M. (2003). The economic performance of regions. Regional Studies, 37.6\&7, 549-578

Puga, D. (2002). European regional policy in light of recent location theories. Journal of Economic Geography,2, 373-406

Rastvortseva, S. N. (2020). An innovative way of changing the trajectory of the previous development of the region's economy. Economy of the region, 16, 1, 28-42. DOI 10.17059/2020-1-3

Russia: principles of spatial development (RPSD). In V.L. Glazychev's website. Retrieved May 5, 2020, from http://www.glazychev.ru/projects/2004_prostrazv/2004_docladprostrazv.htm

Spatial development strategy of the Russian Federation until 2025 (SDSRF) (2019). In Official website of Ministry of Economic Development of Russia. Retrieved August 10, 2020, from http://government.ru/docs/35733/

Thunen, J. H. (1926). Isolated state. Moscow: Economic Life.

Weber, A. (1929). Theory of the location of industries. Chicago: University of Chicago Press.

What we can do for you (SSP). In Smart specialization platform website. From http://s3platform.jrc.ec.europa.eu/ 
PROCEEDINGS OF THE 14th INTERNATIONAL MANAGEMENT CONFERENCE

Zhu, S., He, C., \& Zhou, Y. (2015). How to jump further? Path dependent and path breaking in an uneven industry space. Evolutionary Economic Geography, 1524, 24. DOI: 10.1007/978-98113-3447-4_12 